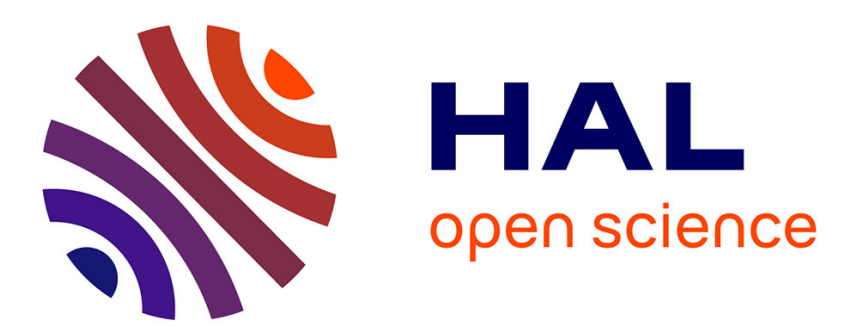

\title{
Term circulation and conceptual instability in the mediation of science: Binary framing of the notions of biological versus chemical pesticides
}

Hélène Ledouble

\section{- To cite this version:}

Hélène Ledouble. Term circulation and conceptual instability in the mediation of science: Binary framing of the notions of biological versus chemical pesticides. Discourse and Communication, 2020, 14 (5), pp.466-488. 10.1177/1750481320917575 . hal-02565304

\author{
HAL Id: hal-02565304 \\ https://hal.science/hal-02565304
}

Submitted on 6 Oct 2021

HAL is a multi-disciplinary open access archive for the deposit and dissemination of scientific research documents, whether they are published or not. The documents may come from teaching and research institutions in France or abroad, or from public or private research centers.
L'archive ouverte pluridisciplinaire HAL, est destinée au dépôt et à la diffusion de documents scientifiques de niveau recherche, publiés ou non, émanant des établissements d'enseignement et de recherche français ou étrangers, des laboratoires publics ou privés. 
Preliminary version of the article Term circulation and conceptual instability in the mediation of science: binary framing of the notions of biological vs chemical pesticides

Name: Hélène LEDOUBLE

To be published in Discourse \& Communication 14(5). 2020

https://doi.org/10.1177/1750481320917575

\begin{abstract}
This article explores the influence of textual structures on the acquisition of knowledge in popularization discourses related to biopesticides. Following a terminological insight into the linguistic and cognitive complexities of the notion, we proceed to a semantic analysis of press articles in major Anglo-Saxon newspapers, focusing on the explanation strategies used by the media to simplify their presentation. We show that in the mediation process, biopesticides (and co-referent terms) are systematically described as being environmentally friendly, and opposed to chemical pesticides, consistently shown to be detrimental to the environment.

We hypothesize that this simplistic binary framing is exploited by journalists as it is easy to understand in a context of agroecological transition and commonly shared distrust for chemical pesticides. In that respect, it proves to be adequate for purposes of explanation and simplification. However, by outlining this discursive process based on duality, we aim to draw attention to the potential misconceptions of plant protection issues in general, and biopesticides in particular. We ultimately demonstrate that when adopting other perspectives (scientific, ontological or ethical), this dual framing proves to be inadequate for the construction of knowledge by any non-expert press reader.
\end{abstract}

Keywords: discourse analysis, competitive denominations, semantics, antonymy, popular science, terminological variation, cognition, framing, binarism, biopesticides, biological pesticides, chemical pesticides, biocontrol 


\section{Term circulation and conceptual instability in the mediation of science: binary framing of the notions of biological $v s$ chemical pesticides}

\section{Introduction}

Concept explanation, as a prototypical textual structure used in scientific mediation, raises a number of linguistic and cognitive questions related to the acquisition of knowledge.

Earlier studies have focused on the interface between textual structures, framing and conceptualization in specialized discourse (cf. for instance Drouin et al., 2017; Faber, 2009; Fernández-Silva, 2016; Fernández-Silva et al., 2014; Freixa, 2006; Pecman, 2018), or in the mediation of science (e.g. Bednarek \& Caple, 2014; Calsamiglia and Van Dijk, 2004; Holmgreen, 2008; Moirand, 2003; Molek-Kozakowska, 2017; Van Dijk, 2003).

In this article, we explore the text/knowledge interface in popularization discourses, with a focus on the understanding of complex scientific notions based on ambivalent semantic structures. This issue is addressed within the framework of a multidisciplinary project dedicated to scientific findings in the field of biocontroli, with a view to identifying potential obstacles to its development. One hypothesis is that outreach communication about biocontrol is unclear, and is due, in part, to denominative variation. This has been confirmed in previous studies on the instability of terms and their definitions in French (cf. Ledouble, 2019, 2020), leading to potential misconceptions of the notions involved.

We here present a complementary analysis of popularizing discourses in English, with a focus on specific types of biocontrol agents, i.e. biopesticidesii. We investigate textual structures containing the term biopesticide(s) as well as semantically-related terms, in order to identify the various denominations and descriptions of products and methods of plant protection. As a result, we outline a recurrent discursive framing which opposes two antagonistic perspectives on this issue - biological versus chemical products and methods - and draw attention to the potential misinterpretations induced by such a binary approach to plant protection in general, and biopesticides in particular.

After introducing the theoretical and analytical framework in Section 2, we present the methodology and data used for the investigation in Section 3 and give an insight into the terminological and cognitive complexity related to biopesticides. Section 4 presents the results of the corpus-based study and the emerging dual framing opposing biological and chemical products and methods. Section 5 discusses conflicting arguments to this binary perspective that lead us to conclude on different cognitive issues related to the construction of knowledge based on popular science discourses. 


\section{Theoretical and analytical framework}

Against the background of pluridisciplinary studies of popularization, the objective of this article is to gain additional awareness on scientific mediation. Our investigation focuses on the notion of biopesticides and provides a critical overview of the means used for naming, explaining and categorizing plant protection products and methods. The analysis is based on "the detailed structures of text and talk that play a role in the presentation of knowledge" (Calsamiglia and Van Dijk, 2004: 371). In press articles dealing with this complex domain of knowledge, there is hardly any extensive contextual definition of the terms employed. We therefore focus on the "prototypic cognitive-discursive type involved in mediation, i.e. explanation" (Moirand, 2003: 177). Our study seeks to "cross this cognitive dimension (the paradigm of ways of referring to a same object such as it may be perceived by the reader) with the communicative dimensions of these press texts" (Moirand, 2003:185), in order to examine the induced knowledge related to this scientific field.

During the analytical process, we also take into account the fact that knowledge is not always explicitly exposed because "[it] is this social nature of shared knowledge that defines presupposition and that allows discourse to be understandable without making all relevant knowledge explicit all the time" (Van Dijk, 2003:86). Hence, the understanding is based on a "social context" (Van Dijk, 1999), whose schematic structure and properties "organize and reduce the complexity of the social situation in such a way that language users have an efficient device to contextualize discourse production and comprehension" (Van Dijk, 1999:131).

Among additional textual devices used to make the notions more straightforward, we also study what Bednarek and Caple (2014) describe as news values, particularly the usual duality between negativity and positivity, ensuring - at least- newsworthiness (Molek-Kozakowska, 2017). This binary perspective is shown to be used for the sake of clarity, and to ascertain consistency and simplicity in the presentation of contrasting perspectives.

Our study of press articles is conducted around the three concepts of "text, context and knowledge, which articulate the discursive, social and cognitive aspects of popularization and of communication in general." (Calsamiglia and Van Dijk, 2004: 385). Before proceeding to the analysis of these textual and cognitive elements, we present the methods and data used for this study, as well as the inherent terminological and cognitive complexity that characterizes biopesticides.

\section{Design of the study: methodology, corpus and terminological insight}

The analytical part of our study lies within the framework of corpus linguistics and textual terminology (Bourigault and Slodzian, 1999; Pearson, 1998). In this section, we start by presenting the methods used for the analysis of denominative variation. 


\subsection{Identification of denominative variants}

In order to identify denominative variation of plant protection products, we initially apply the substitution method (L'Homme, 2004), examining the compatibility between term constituents based on lexico-syntactic patterns (Mel'čuk et al., 1995). Concretely, starting from the main term biopesticide (and the equivalent compound biological pesticide(s)), we determine alternative head terms and modifiers that are semantically-related to either pesticide or biological (bio-), with a view to collecting all potential compounds sharing a semantic relation to the main term.

Subsequently, in order to find regularities in term formation and compare the semantic salience of related terms, we follow Kageura's methodological approach (2002) which defines conceptual categories and intra-term relations according to the distinctive features of term constituents.

This method, originally created to provide a multidimensional concept classification in specialised domains, "is formally equivalent to that of the description of semantic patterns of compounding in general words" (Kageura 2002: 47). We thus find that it can be applied efficiently to the analysis of denominative variation in press articles, based on their semantic proximity.

The contextual explanation of these different product denominations subsequently helps us to either confirm their status of co-referent term (to biopesticides) or to identify other semantic relations between constituents, with a particular focus on the relation of antonymy (cf. Jones, 2002; Murphy et al., 2009).

In a second phase, we replicate this method to identify denominative variants for plant protection methods, with this same objective (identify variants and classify them according to the semantic relations between term constituents).

Starting from established lexico-syntactic patterns and extending the analyses to emerging term constituents, our approach to corpus linguistics is thus both inductive and hypothetico-deductive, and is implemented using the TXM platform (Heiden et al. ,2010).

\subsection{Corpus and data}

Our study is based on a corpus of 244 press articles published between 2010 and 2017 by 11 major national British and American newspapers (cf. below). We compiled all articles containing any of the following keyword: biological control, biocontrol, biological pesticides, biopesticides. biological pest control. This set of keywords was provided by biocontrol experts as sufficiently large to include all relevant articles about biocontrol agents and methods published by (British and American) papers, and restricted enough to avoid off-subject articles.

The corpus thus contains the following sources with the number of corresponding articles between parentheses: The Daily Telegraph (60), The Sun (55), The Guardian (43), The Times (16), 
The Independent (15), The Daily Mail (5), The Financial Times (4), The New York Times (16), The Washington Post (16), The Wall Street Journal (10), USA Today (4) $)^{\mathrm{iii}}$.

We note that the major mass media in the US did not publish as many articles as the British ones (46 versus 198). However, this collection matches the above criteria (time period and keywords) and this does not constitute a limit to this qualitative (more than quantitative) analysis.iv

Before presenting denominative variation in this corpus-based study, we briefly provide a terminological and cognitive insight on biopesticides.

\subsection{A brief review on the terminology of biopesticides}

In the last twenty years, there has been continuing debate over the definition of biocontrol and biocontrol agents. According to a reference article by Eilenberg et al. (2001):

Each discipline uses biological control toward a reduction in disease or pests through the activity of biological control agents (p. 388).

The authors specify that when these agents are micro-organisms, they are called biopesticides, and add: "there are strong arguments in favour of reserving the term biopesticide for preparations containing living (micro-)organisms".

In a later attempt to clarify terms, Pal and McSpadden Gardener (2006) declare:

The term biological control has also been applied to the use of the natural products extracted or fermented from various sources" (...) "while such inputs may mimic the activities of living organisms, non-living inputs should more properly be referred to as biopesticides" (p.2).

Despite the major difference between the status of preparations (based on living inputs or imitating the living), both approaches concur with the general reference definition of the modifier biological, meaning: "of or relating to biology"v, i.e. pertaining to a science concerned with "the study of living organisms".

International institutions provide additional definitions and perspectives to the term. The Food and Agriculture Organisation of the United Nations defines biopesticide as follows:

A generic term, not specifically definable, but generally applied to a biological control agent, usually a pathogen, formulated and applied in a manner similar to a chemical pesticide. (IPPC Glossary, FAO, 2006)

The OECD defines them as:

[products] that can be made from micro-organisms such as bacteria, algae, protozoa, viruses and fungi; semio chemicals; macro organisms and 
invertebrates such as insects and nematodes; as well as botanical extracts.

(Food Standards Programme Codex Committee on Pesticide Residues, 2018)

Facing this instability regarding the status and composition of these products, let us briefly present the legal approach to this subject.

In the United States, the Environmental Protection Agency (EPA) defines biopesticides as follows:

Biopesticides are certain types of pesticides derived from such natural materials as animals, plants, bacteria, and certain minerals. ${ }^{\text {vi }}$

In this definition, we note that the term pesticide is used as a hypernym for biopesticides, be they living or non-living elements.

It is worth mentioning that the term biopesticide (or biological pesticide) is not used in the European legislation: the generic term adopted in the EC Regulation of 2009 vii is "plant protection products", which is defined as follows:

Plant protection products are 'pesticides' that protect crops or desirable or useful plants. [...] They contain at least one active substance [which] is any chemical, plant extract, pheromone or micro-organism (including viruses) ${ }^{\text {viii }}$

These different scientific, institutional and legislative perspectives on biopesticides generate an inherent terminological, cognitive and referential complexity. Indeed, Pal and McSpadden Gardener claimed in 2006 that "the various definitions offered in the scientific literature have sometimes caused confusion and controversy" (2006:2). This statement is still valid nowadays, as confirmed by Bernard (2017: 9), in his recently published work on the subject field. Within this complex framework, our objective is to analyse how non-expert citizens may build their own representation of this issue when reading the national press. With this aim in view, the next section presents the results of corpus-based analyses of textual structures used for the popularization of the information on biological pesticides.

\section{Textual structures and knowledge about plant protection products and methods}

In this section, we first present the various denominations of biological pesticides and semantically-related terms.

\subsection{Biological pesticides: denominative variation and antonymy}

Following Kageura (2002), the head term in a compound carries along the main conceptual category, while the modifier subcategorizes it into potential co-hyponyms. Therefore, once we consider pesticide as the head term, the modifiers are important to identify and discriminate the different types of pesticides mentioned in the corpus. The forthcoming sub-section presents the 
designational paradigm for biological pesticides, applying the methodological frame described above (see section 3.1).

\subsubsection{Biological pesticides and co-referent terms}

In our corpus, the head term pesticide can be modified by the independent modifier biological or its prefixed form bio (-), as in the following extracts:

1) Scientists are working on biopesticides, such as viruses that naturally attack the armyworms. (TheGuardian,2017)

2) FAO field schools have taught farmers to [...] curb its spread with biopesticides made from plants such as neem and tobacco. (TheDailyTelegraph,2018)

3) [...] making biological pesticides - mainly, live bacteria that can kill the worms and caterpillars. (TheWashingtonPost,2017)

Besides morpho-syntactic variation attested above, we can also identify lexical variation. In the following extract, the succession of two sentences implies that the compound natural pesticide corefers to the earlier mentioned bio-pesticide:

4) Scientists who fed bees with high doses of the bio-pesticide Hv1a / GNA observed only a very slight impact on survival [...]. The natural pesticide could be a safer alternative. (TheTimes2014)

The modifier all-natural is also identified in the corpus, creating another co-referent term:

5) The Aim-listed firm has devised an all-natural pesticide that kills botrytis [...], derived entirely from plants. (TheWashingtonPost,2014)

In media studies, it can be challenging to identify the cause for denominative variation, as it is in specialized corpora (cf. Freixa, 2006). No contextual definition indicates whether the choice of a modifier is semantically motivated. In terms of lexical semantics, biological (or bio-) acts as a subcategorization modifier that is related to living organisms (cf. 3.3). We can hypothesize that the use of (all-)natural as a modifier may refer to a subcategory of pesticide based on features that "exist or occur in nature". In the extract 5 above, the referent pesticide Hv1a/GNA is indeed made of spider venom, thus matching the semantics of both biological and natural.

Nevertheless, it can also be used as a mere functional variation (to avoid redundancy, for instance), as it is often the case in French, for instance with régulation biologique and régulation naturelle used as co-referent terms, without any clearly-defined semantic motivation (cf. Ledouble, 2019).

At this stage, we can claim that from a discursive perspective, the two compounds (biological pesticide and natural pesticide) refer to the same product. From a semantic and cognitive point of view, both modifiers subcategorize pesticides according to intrinsic characteristics, their generic type or composition. 
Let us now investigate additional modifiers used in the formation of co-referent compounds, such as safe:

6) Plague of caterpillars threatening food crisis may be halted with safe pesticides. Study suggests biopesticides should be trialled to control the march of armyworm. (TheGuardian,2018)

From a semantic perspective, safe also subcategorizes pesticides, but into a seemingly less objective class, that relates to their impact on the environment. In the paradigm of semanticallyequivalent modifiers identified in this corpus, the following ones have the same discursive function: environmentally-safe, environmentally-friendly, environmentally sustainable. Some other modifiers are to be interpreted in terms of impact on animals, particularly insects, as in the following example:

7) By licensing Eden's fully-regulated, bee-friendly pesticides [...] (TheDailyTelegraph,2014)

Bee-friendly can be grouped with other modifiers found in corpus, with the same discourse function: bee-safe, insect-friendly, wildlife-friendly.

None of these extracts provide any definition to biopesticides or their equivalents, but the reader can infer from co-textual linguistic cues (i.e. such as, mainly, in the extracts 1 and 3) that these pesticides refer to living elements, and/or are based on natural elements (i.e. made/derived from plants in extract 2 or 5 ), and are harmless to biodiversity in general (the environment and animals) (cf. extracts 4, 6 and 7).

We now turn to the presentation of semantically-related modifiers, sharing the same head term pesticide(s), but contextually presented as antonyms.

\subsubsection{A variety of antonymous relations}

In this article, we are considering the relation of antonymy in its broad sense, characterizing "all types of lexical opposite" (cf. Cruse, 1986: 204). Following Murphy et al. (2009), the analysis of discursive antonymy implies the consideration of the syntagmatic and paradigmatic construction of information. In our corpus, we find a variety of semantic structures in which biological pesticides are opposed to chemical pesticides. In the following extract for instance, the Bacillus thuringiensis israelensis (Bti) (a biopesticide) is "used in place of" chemical pesticides, exemplifying transitional antonymy (Jones, 2002):

8) It [Bti] is now widely used in place of chemical pesticides. (TheNewYorkTimes, 2014) 
With syntagmatic constructions such as in place of (or from $\mathrm{X}$ to $\mathrm{Y}, \mathrm{X}$ gives way to $\mathrm{Y}, \mathrm{X}$ replaces $\mathrm{Y}$, etc.), journalists convey a "change from one [...] activity or state, to another" (Murphy et al., 2009: 2162).

This "transition" from chemical pesticides to biological ones is constantly reported in our corpus:

9) [...] a pioneer in the development of environmentally safe control agents to replace broad-spectrum chemical pesticides. (TheNewYorkTimes, 2014)

In this example, biopesticides are referred to as environmentally safe control agents in a relation of transitional antonymy with chemical pesticides. A more complex compound is forged with the adjoined modifier (here "broad-spectrum"), that conveys information as to their modus operandi: the fact that these chemical pesticides are non-selective and do not target any specific pest (the modifier kill-everything has also been attested in the corpus).

From a lexical semantics perspective, the adjective chemical means: "of or used in chemistry", chemistry being defined as "the scientific study of the structure of substances". As it appears, there is no definitional opposition between the modifier biological (related to living organisms) and chemical (related to the structure of substances). From the perspective of corpus semantics though, they are repetitively presented as discursive opposites.

It is worth noting that the modifier chemical can also be omitted:

10) Broad spectrum pesticides tend to kill insects in general, without regard to their trophic level (TheIndependent, 2018)

In this extract, pesticides are implicitly subcategorized as chemical pesticides, based on the commonly shared assumption that the word pesticide generally refers to a chemical product, produced artificially. The latter is then portrayed as being harmful to animals, as illustrated below:

11) Existing pesticides often harm both pests and beneficial insects. (TheGuardian,2018)

In line with this principle, we find an important paradigm of semantically-equivalent modifiers that refer to the negative impact pesticides have on the environment:

12) Many farmers are attempting to control armyworm [...] through the use of highly hazardous pesticides. (TheGuardian,2018)

Hazardous pesticides are semantically opposed to the aforementioned safe and (insect-)friendly group. In much the same way, harmful pesticides are presented in a transitional form of antonymy, as exemplified in the extract below:

13) "Sexy plants"ix are on the way to replacing many harmful pesticides. (TheGuardian,2018)

Besides, chemical as a noun can also become the new head term: 
14) the pesticides [...] which typically kill a broad spectrum of pests. These chemicals are environmentally harmful. (TheNew YorkTimes, 2016)

The semantic equivalence between pesticides and chemicals can be explained by the relation of meronymy between the two (pesticides being composed of chemicals ${ }^{\mathrm{x}}$ ). Taken as part for a whole, chemicals can therefore be equally subcategorized and pictured as harmful:

15) There's a risk that farmers will buy toxic chemicals (TheGuardian,2018) or qualified with a general evaluative modifier referring to the negative image of a product, such as nasty in the following extract:

16) Their flowers use nature's own defense instead of nasty chemicals. (TheDailyTelegraph,2014)

The precise semantic salience of each of these modifiers is not always straightforward, in particular for the lay reader. In the absence of contextual definitions, the latter can essentially gather that they are all presented in a relation of antonymy with biological pesticides, and unquestionably depicted as having a negative impact on biodiversity.

The analysis of the totality of discursive contexts shows a striking binary opposition between products that would be either biological or chemical, and thus, carrying along a respectively positive or negative image. Table 1 synthetizes this systematic opposition between two types of products, along five major sub-categorization relations between head terms and modifiers (based on Kageura's framework, to be read from left to right):

\begin{tabular}{|c|c|c|c|}
\hline \multirow{2}{*}{$\begin{array}{c}\text { CONCEPTUAL } \\
\text { CLASS } \\
\text { HEAD } \\
\end{array}$} & \multirow{2}{*}{$\begin{array}{c}\text { SUB-CATEGORIZATION } \\
\text { MODIFIER }\end{array}$} & \multicolumn{2}{|c|}{ LEXICON } \\
\hline & & Positive & Negative \\
\hline \multirow{5}{*}{$\begin{array}{l}\text { PESTICIDE / } \\
\text { CHEMICAL }\end{array}$} & (GENERIC)TYPE & $\begin{array}{l}\text { biological } \\
\text { bio- }\end{array}$ & chemical \\
\hline & ORIGIN/COMPOSITION & $\begin{array}{l}\text { natural } \\
\text { all-natural }\end{array}$ & $\begin{array}{l}\text { synthetic } \\
\text { neonicotinoid }\end{array}$ \\
\hline & $\begin{array}{l}\text { IMPACT ON BIODIVERSITY } \\
\text { (PLANTS, ANIMALS, HUMAN BEINGS) }\end{array}$ & $\begin{array}{l}\text { bee-friendly } \\
\text { bee-safe } \\
\text { environmentally-friendly } \\
\text { environmentally-sustainable } \\
\text { environmentally safe } \\
\text { insect-friendly } \\
\text { safe } \\
\text { sustainable } \\
\text { wildlife-friendly }\end{array}$ & $\begin{array}{l}\text { abrasive } \\
\text { aggressive } \\
\text { caustic } \\
\text { dangerous } \\
\text { deadly } \\
\text { environmentally-harmful } \\
\text { harmful } \\
\text { hazardous, } \\
\text { risky } \\
\text { toxic, } \\
\text { unsafe }\end{array}$ \\
\hline & MODE OF ACTION & $\begin{array}{l}\text { specific } \\
\text { selective }\end{array}$ & $\begin{array}{l}\text { broad-spectrum, } \\
\text { kill-everything } \\
\text { quick-fix } \\
\text { systemic }\end{array}$ \\
\hline & IMAGE & green & $\begin{array}{l}\text { nasty } \\
\text { unpopular }\end{array}$ \\
\hline
\end{tabular}


Table 1 - Conceptual patterns for plant protection products and contrastive lexicon

From the perspective of lexical semantics, the lexicon in each column conveys a specific meaning (e.g. chemical vs. synthetic vs. caustic, etc.), but from a discursive perspective, these units often appear to be contextually interchangeable. Being repeatedly opposed on the scale of positivity/negativity, the purpose of each lexical unit seems to be the framing between the two contrasted perspectives. Indeed, as Bednarek \& Caple (2014) and Molek-Kozakowska (2017) have shown, this oscillation between negativity and positivity is an important stylistic pattern in popular science discourses. The negative framing "may be realized through negative evaluative modifiers, reference to negative emotion and attitude, or lexical items that refer to undesirable states and actions" (Molek-Kozakowska, 2017: 74). But it may also be based on more neutral items (i.e. here synthetic), that are related to a socially-based rhetoric or belief, namely, the social conviction that pesticides are produced artificially and therefore troublesome. Conversely, science journalism also reports more positive perspectives: "the nature of scientific coverage is such that new research reports may give a sense of security by offering knowledge, explanation, warning or remedy, which can be evaluated as positive." (Molek-Kozakowska, 2017: 75). These opposed discursive processes can therefore simplify argumentation by triggering emotional reactions from the public. As Rastier (2011) made it very explicit, "binarism is appealing as it is easy to understand. Experimental research work in the last century on word association and mental lexicon organization has always confirmed that the antonym comes to mind in the shortest time. The relation of antonymy is thus often used in support of propaganda, as it necessitates very little effort" (2011: 121)xi.

This analysis can also be related to studies of semantic prosody (cf. Sinclair, 2000), expressing "attitudinal and pragmatic meaning" (p.200), with a potentially negative connotation associated to a lexical unit. Sinclair's assumption can here be applied to the form chemical, tainted with negativity: "The selection of the item is controlled by the prosody, because the whole point of expressing oneself in this way is to pre-evaluate the actions, which would otherwise be positively evaluated by the reader/listener." (p.201)

In order to present a broader perspective on this binary framing, the next sub-section deals with the generic notion of methods of plant protection, emphasizing the parallel dualistic opposition between two types of methods.

\subsection{Biological (control) methods: denominative variation and antonymy}

A second outcome of the substitution method applied to our corpus is the identification of new head terms, collocating with modifiers identified so far, and semantically-related to biopesticides. 


\subsubsection{Biological (control) methods and co-referent terms}

Our textual analysis reveals that the three head terms method, treatment, or control, can be used as hypernyms for pesticides, and modified by successive qualifiers. Table 2 presents a syntagmatic and paradigmatic synthesis of co-referent compounds identified in corpus:

\begin{tabular}{|l|l|l|}
\hline Modifier 1 & Modifier 2 & HEAD TERM \\
\hline biological & natural & METHOD \\
\hline biological & & TREATMENT \\
\hline natural & biological & CONTROL \\
\hline organic & & CONTROL \\
\hline alternative & & CONTROL \\
\hline sustainable & natural & CONTROL \\
\hline
\end{tabular}

Table 2- Contextual hypernyms for biopesticides and modifiers

Here are a few contexts illustrating these usages:

17) the benefits of biological or "natural" methods [...] (TheDailyTelegraph, 2016)

18) There are biological treatments in the form of water-in nematodes. (TheDailyTelegraph, 2016)

19) [Bug] collection will [...] be a resource for scientists who study natural controls on the environment. (TheGuardian, 2017)

20) Leatherjacket Killer, which is an organic control containing eelworms. (TheSun,2016)

21) producers [...] are starting to reduce their reliance on chemicals and develop alternative controls for fruit fly. (TheGuardian, 2016)

From a purely semantic perspective, the modifier alternative does not share any semantic properties with biological or natural. However from contextual information, the reader understands that these terms co-refer to (positive) methods using biopesticides. An extensive paradigm of semantically-related head terms and modifiers confirms the positive connotations of such practises:

22) The ante has been upped in the past year or two about the need for environmentally friendly pest control. (TheDailyTelegraph, 2016)

23) Natural biological control is all part of the garden's ecosystem. (TheTimes, 2017)

24) We are working towards sustainable natural control of Japanese knotweed. (TheDailyTelegraph, 2012)

Let us now consider what the press describes as contrasting methods of plant protection.

\subsubsection{Antonymous relations and methods}

In the same way as for plant protection products, the relation of antonymy between (biological and chemical) methods is clearly conveyed by linguistic cues. We find for instance, the form instead (of) used for the expression of negated antonymy between methods. Following Jones (2002), negated antonymy is "the co-occurrence of an antonymous pair within a framework that 
negates one antonym as a device to augment the other" (2002: 88). Typical frameworks involve lexico-syntactic structures such as: not Y but X, X opposed to Y, or X instead of Y, like in:

25) The general idea of using biological control instead of pesticides is good. (TheWallStreetJournal, 2013)

The chemical treatments are logically portrayed as being harmful to the environment:

26) But nearby plantations use chemical farming methods, which is causing pollution. (TheGuardian,2016)

We also find a paradigm of modifiers that are not semantically equivalent to chemical (e.g. conventional, agricultural), but which create discursive compounds co-referring to chemical (control) methods:

27) conventional pest control means such as crop dustings of pesticides were out of the question. (TheWashingtonPost, 2012)

Conventional semantically offsets the modifier alternative seen above, qualifying time-anchored practises, i.e., traditional chemical methods used in agriculture (versus alternative, more modern methods). In the same vein, the modifier agricultural discursively refers to chemical (control) methods:

28) [S]cientists and Big Pharma [...] continue their high-profile spat about environmental protection versus agricultural pest control. (TheDailyTelegraph, 2016)

Again, from the perspective of lexical semantics, agricultural refers to the application domain (or usage) of pesticides (opposed to sanitary indoor pesticides). However, in terms of interpretation (cf. extract 28), based on the relation of negated antonymy (and the linguistic cue versus) the reader gathers that agricultural is contextually interchangeable with traditional or conventional, the three modifiers referring to standard (chemical) methods used in agriculture. None of these modifiers can be considered as synonyms. However, using the context and recollecting the commonly shared opposition between biological and chemical, readers will effortlessly frame the methods on either side of the evaluation scale. Five similar conceptual categories of methods emerge, all outlining the dual polarity (positive/negative), as described in Table 3 below.

\begin{tabular}{|c|c|c|c|}
\hline CONCEPTUAL & SUB-CATEGORIZATION & \multicolumn{2}{|c|}{ LEXICON } \\
\hline HEAD & MODIFIER & Positive & Negative \\
\hline & (GENERIC)TYPE & biological & chemical \\
\hline & ORIGIN/COMPOSITION & $\begin{array}{l}\text { natural } \\
\text { organic }\end{array}$ & neonicotinoid \\
\hline $\begin{array}{l}\text { METHOD } \\
\text { CONTROL }\end{array}$ & $\begin{array}{llll}\text { IMPACT } & \text { ON BIODIVERSITY } \\
\text { (PLANTS, } & \text { ANIMALS, } & \text { HUMAN } \\
\text { BEINGS) } & & \end{array}$ & $\begin{array}{l}\text { ecologically-friendly } \\
\text { environmentally-friendly } \\
\text { environmentally safe } \\
\text { environmentally-sound }\end{array}$ & $\begin{array}{l}\text { dangerous } \\
\text { detrimental } \\
\text { harmful }\end{array}$ \\
\hline
\end{tabular}




\begin{tabular}{|l|l|l|l|}
\hline TREATMENT & sustainable & \\
\cline { 2 - 4 } & MODE OF ACTION & $\begin{array}{l}\text { precision } \\
\text { specific }\end{array}$ & $\begin{array}{l}\text { quick-fix } \\
\text { systemic }\end{array}$ \\
\cline { 2 - 4 } & DOMAIN/USAGE RELATED & $\begin{array}{l}\text { alternative } \\
\text { alternate }\end{array}$ & $\begin{array}{l}\text { agricultural } \\
\text { conventional } \\
\text { traditional }\end{array}$ \\
\hline
\end{tabular}

Table 3- Conceptual patterns for plant protection methods and contrastive lexicon

Before questioning the cognitive relevance of this binary framing, we conclude Section 4 by a few perspectives on the observed term-constituent combinations.

\subsection{Unlimited combinatorial perspective on term constituents}

In this study, we have initially identified 53 different modifiers to pesticides and/or methods, each of them creating a compound with a specific semantic relation to biopesticides. Out of these 53 modifiers, a vast majority of them (46) can be classified according to the dual framing, embodying either a positive or negative perception, as shown in Table 1 and 3xii.

This linguistic variation and plasticity in designating products or methods in popular science can in part be explained by the continuum between terms and words. Indeed, as "terminology shares its linguistic form with the general vocabulary, it tends towards using the full flexibility of natural language, not only in its lexical-formal dynamics but also in its capacity of establishing dynamic relations between lexical items and meaning" (Kageura, 2002: 15).

This lexical proliferation is even more striking as we consider additional compounds, appearing only once in the corpus. For instance, the compound nematode control is forged, co-referring to biological control methods, as well as natural defense. These terms contrast with contextual antonyms such as synthetic compounds or systemic insecticides.

Besides, other combinations emerge, in which a modifier takes the place of a head term in a new compound. For instance, the modifier alternative in alternative control becomes the head term in a green alternative, referring to (bio)pesticides and co-referring with a sustainable alternative or safer alternative, complementing a seemingly unlimited paradigm of potential term-constituent alternation.

Geeraerts et al. (1994) refer to this phenomenon as "onomasiological variation" (p. 4) in which "a particular referent may be identified as a member of different categories" (if it conveys a conceptual distinction). Yet as we have previously observed, the conceptual category here does not seem to be that important. What is significant is the fact that with little domain knowledge and enough socially-shared knowledge, the reader can easily rank the product or method on either 
side of the binary framing. Just as Geeraerts et al. conclude from their extensive study of the terminology of clothing, and particularly their insight into onomasiological variation, "the major differences that we have found appear to involve pragmatic, situational factors rather than sociolinguistic or geographical ones". (1994:153)

This pervasive binarism could be investigated further with the analysis of rhetoric and style, and particularly the universal metaphor opposing good and evil. The study of the concepts of biological vs chemical pesticides from the perspective of conceptual metaphor (cf. Lakoff, 1980, or Kövecses, 2005) deserves a full-fledged analysis, and will be addressed in a later study. However, we here present a relevant illustration by quoting two corpus extracts, in which the ancient biblical reference Armageddon is used as the head term, being modified both by ecological and chemical:

29) Last year scientists warned of "ecological Armageddon" as the number of flying insects has plummeted by 75 per cent in the past 27 years (TheIndependent, 2018)

30) [...]1 per cent that survive the chemical Armageddon (TheDailyMail 2010)

This universal reference to Armageddon, opposing the forces of good and evil, is here qualified by contrasting modifiers, confirming the pervasive bi-polarization in the process of explaining complex notions.

However what we intend to demonstrate is that such a simplistic vision on the question of plant protection may be deceptive and lead to inaccurate interpretations. In the following section, we present different perspectives on these issues.

\section{Discussion: conflicting arguments and cognitive conundrum}

Binarism can be questioned if the reader considers other corpus extracts, which, even though less common, shed a different light on the contrast. In this section, we discuss conflicting textual structures and arguments, starting with the recollection of the ontological status and properties of products and methods of plant protection.

\subsection{Opposite versus complementary methods}

The following corpus extract specifies that - ontologically-wise - rather than being contrary, the two contrasting control methods also have common points:

31) Control is achieved [...] either with a biological control based on nematodes [...], or chemical control (TheDailyTelegraph, 2015)

The linguistic elements either/or enable the reader to gather that the two "controls" refer to plant protection methods. Jones (2002) and Murphy et al. (2009) call this phenomenon 'coordinated antonymy', whose semantic effect is to "signal inclusiveness of exhaustiveness of scale" (Jones 2002: 61), but paradoxically, "in which the distinction between the two opposites is neutralized 
(Murphy et al., 2009). The same principle is exemplified in the following extract, with the form both introducing natural and chemical (treatments):

32) Before specific vine weevil killer treatments (both natural and chemical) were developed (TheDailyTelegraph,2016)

We can interpret that the two "treatments" also share common properties, as being two cohyponymic methods of plant protection. Cruse (1986) had already tried to account for this apparent contradiction:

"This paradox of simultaneous difference and similarity is partly resolved by the fact that opposites typically differ along only one dimension of meaning: in respect of all other features they are identical, hence their semantic closeness." (Cruse, 1986: 197)

This perspective is in line with a principle which has recently gained importance in the field of plant protection, both scientifically and legally. It is called Integrated Pest Management (IPM) and favours complementary approaches to plant protection. IPM establishes the fact that chemical and biological methods are just two possible treatments to fight pests, together with mechanical, agronomical, physical, cultural methods, etc. (for detailed explanations concerning IPM, see Ledouble, 2020).

Another related example is the (rare) use of the morphological antonym to chemical, that is nonchemical ( 2 occurrences only in the whole corpus):

33) You can find all sorts of other non-chemical controls for garden pests (TheDailyTelegraph, 2015) ${ }^{\text {xii }}$

From this extract (and without contextual details), the reader may conclude that if it is nonchemical, it should be biological. Firstly because of the pervasive binarism seen so far, and secondly because earlier studies have shown that "while morphological opposites are readily available in English, we tend to prefer lexical opposites in contrastive constructions" (Murphy, 2006: 16), when these pairs are available in the language (biological/chemical). However in reality, non-chemical can refer to other methods, as this other extract can attest:

34) No current chemical or mechanical method offers reliable long-term control of Japanese knotweed (TheDailyTelegraph, 2011)

Mechanical (only 1 occurrence in the corpus) is presented as another method of plant protection, such as cultural (1 occurrence too):

35) [T] here are cultural controls: an effective way of getting rid of aphids is to blast them off with jets of water (TheDailyTelegraph, 2012)

We can conclude from this part that the simplified cognitive binarism, if taken as is, may lead to confusion, or at least challenge conceptual representations built by the reader. Indeed, biological 
and chemical methods are not conflicting but complementary, but only a very limited number of extracts makes it explicit.

We now turn to the very nature or composition of biological and chemical products.

\subsection{Are chemical pesticides all bad?}

Let us analyze a few isolated corpus extracts which question the apparently clear-cut binary perspective. From the following extract:

36) Rebecca Burn-Callander meets a British firm making pesticides that are kind to bees (TheDailyTelegraph, 2014),

any non-expert reader understands that pesticides can also be insect-friendly. And from this one:

37) Scientists have created a "biopesticide" from two naturally occurring chemicals- snowdrops and spider venom (The Independent, 2014),

the reader can gather that this biological pesticide is "created" by scientists (hence through chemical synthesis) and is composed of chemicals (occurring in nature). It would then perfectly match the general definition of a "chemical pesticide".

Finally, this extract explains that chemicals can also be produced by animals:

38) While feeding, they [aphids] often secrete chemicals into the host plant (TheDailyTelegraph, 2012)

A chemical can therefore be produced without any human intervention, or any sort of man-made chemistry. In that case, a chemical is a natural product and thus corresponds to the definition of a "natural pesticide" (and it could also semantically and rationally be referred to as a "natural chemical").

All these observations show that there should not be any semantic prosody attached to chemical pesticides ${ }^{\mathrm{xiv}}$. We can then infer that maintaining the good versus evil framing (by opposing what is "related to biology" or "to chemistry") proves to be adequate for discursive purposes of explanation, but inadequate for the construction of knowledgexv.

The final two forthcoming subsections present additional conflicting perspectives in the interpretation of discursive structures, starting with the question of time and context.

\subsection{Time-related perspective on products and methods}

If we now move from ontological properties of concepts to corpus-based semantics, we note that these texts are context-dependent, and can be influenced by circumstantial, social or discursive elements. 
When reading the following extract:

39) There are many kinds of traditional methods to fight off the aphids (TheDailyTelegraph, 2012),

what immediately comes to mind are the traditionally used chemical methods described above. However, if we read further: "[...] to fight off the aphids, from flour sprays to cow urine".

Any reader understands that traditional in this extract actually refers to 'natural' methods, used long before chemical methods existed. Another example of potential time-related confusion is exemplified in the following extract:

40) [E]nvironmental groups, that contend fertilizers and pesticides are used excessively in modern agriculture (TheWallStreetJournal, 2012)

From the perspective of lexical semantics, modern could be considered as an antonym of traditional and conventional methods. However, in this example, modern agriculture is used as a discursive equivalent to what we earlier described as traditional agriculture, i.e. using chemical methods (modern referring to the post-industrial revolution, where using synthetic products proved to be efficient on a large scale). This apparent discursive paradox, in which modernity is equivalent to tradition, can be resolved by the reader's interpretative capacity, based on context analysis and a personal or social knowledge on the evolution of plant protection methods.

We have finally identified a few extracts providing a completely different perspective on biopesticides, that we examine in the next sub-section.

\subsection{Are biopesticides flawless?}

Considering biopesticides merely as "good for the environment" is one-dimensional, and over simplistic. Indeed, the antagonistic (positive) connotation of chemical methods is mentioned in a few extracts:

41) pest control, too, often involves sulfur, coppers or biological pesticides, which require many more tractor trips to deliver than their conventionalfarming equivalents, thus increasing carbon in the atmosphere. (TheWallStreetJournal,2015).

Connecting pollution to biological control methods offers a contrasting vision to the classical one described above, and, in terms of building knowledge, it may also be considered as important. Among other similar counter-arguments, we find the following:

42) the bio-pesticide market is very complex. Some companies use mosquitos to combat pests. But most of our customers prefer to deal with a chemical than an animal - it's what they're used to. (TheDailyTelegraph, 2014)

This can be related to earlier studies by Holmgreen (2008), Bauer (1998) and before them, Frewer et al. (1997), who built evidence of the fact that, in the field of biotechnology, the lay citizen (here embodied by the "customer") is not at ease with scientific applications dealing with animals or 
human beings in general: "applications involving plants or micro-organisms are more acceptable than those involving animals" (Frewer et al., $1997: 100$ ). This principle is quite puzzling in our case study, precisely because of the unstable status of biopesticides described in 3.3, based on plants, microorganisms or bigger animals (like insects).

Besides the nature of the application (plant protection), "public assessment of biotechnology" depends, as Holmgreen recalls, on "the relation between risk, benefits, and ethics" (Holmgreen 2008:100). In our case study, two corpus extracts convey the worrying issue of the influence of man, over nature:

43) Importing tiny insects to tackle Britain's Japanese knotweed problem could easily backfire on us [...] Meddling with nature is always controversial. (TheDailyTelegraph, 2010)

44) Described as a "voracious invader" with a frightening appetite for other ladybirds [...], the harlequin causes understandable alarm. (TheGuardian, 2016)

The lexicon used in those (rare) extracts is particularly negative (backfire, controversial, frightening, alarm), and announces a very different perspective on the subject, but that remains almost insignificant, facing the generalized positive image of biopesticides in the media.

We now turn to the conclusive part of this article, at this stage of the project ongoing analysis.

\section{Conclusions and perspectives}

In this article, we have given evidence of the impact of textual structures on information and knowledge that can be built by any non-expert citizen, based on reading and interpreting popular science articles in the press. We have shown that on the one hand, a binary framing can facilitate explanations of complex scientific notions by helping the reader to choose between two opposed and seemingly unambiguous perspectives. Nevertheless, our analysis also shows that such a dichotomy, added to the proliferation of apparently unrestricted term-constituent combinations, creates a global terminological and cognitive instability, and potential mass misconception regarding this area of biotechnology.

As far as transmission of knowledge is concerned, the question that remains is that of relevance, and whether -or not - this information is "adequate as a basis for further learning" (Calsamiglia and Van Dijk, 2004: 386). Our study seems to show that the answer depends, among other elements, on the scientific knowledge of the reader, and if he is able to question the arguments to the case. Another question raised by this study is related to the implicit correlation between biological and positivity versus chemical and negativity. It does send the reader back to the ancient 
opposition between "those who support science as an inescapable factor of progress versus those who support nature, for whom science is dangerous and destabilizing". (Moirand, 2003: 196). However in the case of biological control, which aims at creating products or methods that mimic natural processes, this antagonism is being looked into from a different perspective. These issues are all the more delicate as we turn to interlinguistic perspectives. Indeed, the term pesticide is strongly connotated in some languages, particularly in French where it is an equivalent to "produit phytosanitaire", and therefore, the simple term pesticide suffers from a severe generalized distrust for French speakers. Now that the readers have built their knowledge on this principle, it may be challenging to reframe them into thinking that pesticides, be they biological or chemical, should not be affected by any semantic prosody. In the lines of previous linguistic studies in the project, our goal is to reveal complex interlinguistic and cognitive issues related to biological control, in an attempt to emphasize terminological areas which may need clarification, as scientists have been yearning for in the last two decades.

\section{References}

Bauer M (1998) The medicalization of science news: from the 'rocket-scalpel' to the 'genemeteorite' complex. Social Science Information 37(4): 731-751.

Bednarek M and Caple H (2014) Why do news values matter? Towards a new methodological framework for analyzingnews discourse in Critical Discourse Analysis and beyond. Discourse \& Society 25/2: 135-158.

Bernard JL (2017) Biocontrôle en protection des cultures: Périmètre, succès, freins, espoirs. Paris: L'Harmattan.

Bourigault D and Slodzian M (1999) Pour une terminologie textuelle. Terminologies nouvelles 19: 29-32.

Calsamiglia H and Van Dijk T (2004) Popularization discourse and knowledge about the genome. Discourse \& Society 15(4): 369-389.

Cruse DA (1986) Lexical Semantics. Cambridge: Cambridge University Press.

Drouin P and Francoeur A and Humbley J and al. (Eds) (2017) Multiple Perspectives on Terminological Variation. Amsterdam: John Benjamin.

Eilenberg J and Hajek A and Lomer C (2001) Suggestions for Unifying the Terminology in Biological Control. BioControl 46: 387-400.

Faber P and León Araúz P and Prieto Velasco JA (2009) Semantic relations, dynamicity, and terminological knowledge bases», in Current Issues in Language Studies, 1(1), pp.1-23.

Fernández-Silva S (2016) The cognitive and rhetorical role of term variation and its contribution to knowledge construction in research articles, Terminology 22(1), Amsterdam, John Benjamins Publishing Company, p. 52-79. 
Fernández-Silva S and Freixa J and Cabre T (2014). A method for analysing the dynamics of naming from a monolingual and multilingual perspective. Rita Temmerman; Marc van Campenhoudt (eds.). Dynamics and terminology: an interdisciplinary perspective on monolingual and multilingual culture-bound communication. Amsterdam: John Benjamins Publishing Company :183-211.

Freixa J (2006) Causes of Denominative Variation in Terminology: A Typology Proposal. Terminology 12(1): 51-77.

Frewer LJ and Howard C and Shepherd R (1997) Public Concerns in the United Kingdom about General and Specific Applications of Genetic Engineering: Risk, Benefit, and Ethics, Science, Technology, and Human Values 22(1): 98-124

Geeraerts D and Grondelaers S and Bakema P (1994) The Structure of Lexical Variation: Meaning, Naming, and Context. Berlin: Mouton De Gruyter.

Heiden S and Magué JP and Pincemin B (2010). TXM : Une plateforme logicielle open-source pour la textométrie - conception et développement. In Proceedings of 10th International Conference on the Statistical Analysis of Textual Data (JADT 2010), ed. by S. Bolasco, I. Chiari and L. Giuliano, Roma: Edizioni Universitarie di Lettere Economia Diritto: 1021-1032.

Holmgreen LL (2008) Biotech as 'biothreat'? Metaphorical constructions in discourse. Discourse \& Society 19(1): 99-119.

Jones S (2002). Antonymy: A Corpus-based Approach. Routledge, London.

Kageura K (2002). The Dynamics of Terminology: A Descriptive Theory of Term Formation and Terminological Growth. Amsterdam/Philadelphia: John Benjamins Publishing.

Kövecses Z (2005). Metaphor in culture: Universality and variation. Cambridge/New York: Cambridge University Press.

Lakoff G and Johnson M (1980) Metaphors We Live By. Chicago: University of Chicago Press.

Ledouble H (to be published 2020) Contextes et connaissances dans les discours de vulgarisation scientifique : dynamiques définitoires et problématiques cognitives. In Des corpus numériques à la modélisation linguistique en langues de spécialité, ed. by C. Frérot and M. Pecman. Grenoble: Éditions UGA.

Ledouble H (2019) Vulgarisation scientifique et médiatisation de la science: instabilité terminologique dans le domaine de la lutte biologique, Terminology 25(1), Amsterdam, John Benjamins Publishing Company, p. 60-92.

L'Homme MC (2004) La terminologie : principes et techniques. Montréal: Presses de l'Université de Montréal.

Mel'čuk I and Clas A and Polguère A (1995) Introduction à la lexicologie explicative et combinatoire. Louvain-la-Neuve (Belgique): Duculot.

Moirand S (2003) Communicative and Cognitive Dimensions on Science in the French Media. Discourse Studies 5(2): 175-206. 
Molek-Kozakowska K (2017). Communicating environmental science beyond academia: Stylistic patterns of newsworthiness in popular science journalism. Discourse \& Communication, 11(1), 6988.

Murphy ML and Paradis C and Willners C and Jones S (2009). Discourse functions of antonymy: a cross-linguistic investigation of Swedish and English. Journal of Pragmatics, 41(11), 2159-2184.

Murphy ML (2006) Antonyms as lexical constructions: or, why paradigmatic construction is not an oxymoron. Constructions, SV1 (8). pp. 1-37. ISSN 1860-2010

Pal KK. and McSpadden Gardener B (2006) Biological Control of Plant Pathogens. The Plant Health Instructor DOI: 10.1094/PHI-A-2006-1117-02.

Pearson J (1998) Terms in context. John Benjamins Publishing Company.

Pecman M (2018) Langue et construction de connaisSENSes. Energie lexico-discursive et potentiel sémiotique des sciences. Paris : Editions L'Harmattan.

Rastier F (2011) La Mesure et le Grain. Sémantique de corpus. Paris: Honoré Champion.

Sinclair J (2000) Lexical grammar. Naujoji Metodologija 24: 191-203.

Van Dijk T (1999) Context Models in Discourse Processing, in H. van Oostendorp et S. Goldman (eds.), The Construction of Mental Representations During Reading, London, Lawrence Erlbaum, pp. 123-148.

Van Dijk T (2003) The Discourse-Knowledge Interface, in R. Wodak and G. Weiss (eds) Critical Discourse Analysis. Theory and Interdisciplinarity, London: Palgrave : 85-109.

\footnotetext{
${ }^{i}$ Biological control, or biocontrol "means the use of living organisms or their products to prevent or reduce the losses or harm caused by pest organisms", in the domain of plant protection. URL: https://www.iobcglobal.org/statutes_IOBC-Global.pdf.

ii "Biopesticides are certain types of pesticides derived from such natural materials as animals, plants, bacteria, and certain minerals" (source: Environmental Protection Agency). But definitions differ depending on sources (cf. 3.3).

iii The original corpus (in the Factiva database) included the 14 most widely read national papers (7 British and 7 American), but 3 American papers (The Los Angeles Times, NY Daily news, The New York Post) did not publish any article containing these keywords during that period.

iv If need be, this difference in numbers can somewhat be compensated by the fact that American articles are longer: the American sub-corpus is almost a third of the size of the total corpus (with 41596 word forms, versus 125123 word forms for the British sub-corpus).

$\checkmark$ This definition and all the following ones in this article are cited from COBUILD Advanced English Dictionary (HarperCollins Publishers 2019). We intentionally use a general language dictionary for the interpretation of terms, as press readers would tend to use this type of reference (rather than a terminological database). We also need to specify that the definitions in American English are extremely similar to the ones presented here in British English.

vi URL: https://www.epa.gov/pesticides/biopesticides

vii URL: http://data.europa.eu/eli/reg/2009/1107/2018-11-10

viii URL: https://ec.europa.eu/food/plant/pesticides_en

ix The compound « sexy plants » refers to plants that are genetically modified to produce sex pheromones (considered as a biopesticide) of moths, which frustrate the pests' attempt to mate.

${ }^{x}$ As the terminological database used by the FAO specifies: URL: http://aims.fao.org/aos/agrovoc/c_5739

${ }^{x i}$ Original text (our translation): «le binarisme séduit parce qu'il est facile à comprendre. Les travaux expérimentaux menés depuis un siècle sur les associations et l'organisation du lexique mentale ont toujours
} 
confirmé que l'antonyme vient à l'esprit dans le temps le plus court. Aussi, la relation d'antonymie reste telle privilégiée par les discours de propaganda, car elle exige peu d'efforts". (Rastier, 2011:121)

xii The remaining 7 modifiers that do not match this dual framing can be split up in two categories: 1- new, approved, effective, licensed, regulated. 2- non-chemical, chemical-free, the semantics of the last two will be discussed in 5.1

xiii One occurrence only of chemical-free has also been attested

xiv An article from The New Scientist (November 2014) attests to this socially-shared negative feeling about chemicals: https://www.newscientist.com/article/mg22429973-100-chemical-is-not-a-dirty-word/

${ }^{\mathrm{xv}}$ The term biochemical (largely used by scientists or legislators, but absent from our corpus) can attest that biological and chemical are not antagonistic : "the study of the chemical compounds, reactions, etc, occurring in living organisms" (COBUILD Advanced English Dictionary) 